\title{
Chest wall tumour following iodized talc pleurodesis
}

\author{
JOHN W. JACKSON and M. H. BENNETT \\ Thoracic Surgical Unit, Harefield Hospital, Harefield, Middlesex \\ and Group Histopathology Department, Mount Vernon Hospital, Northwood, Middlesex
}

\begin{abstract}
Jackson, J. W., and Bennett, M. H. (1973). Thorax, 28, 788-793. Chest wall tumour following iodized talc pleurodesis. A man of 37 had an iodized talc pleurodesis carried out for recurrent spontaneous pneumothorax. There was no history of industrial exposure to asbestos. Two years later he presented with pain in the right chest and radiographs at that time showed some localized pleural thickening at the site of the thoracoscopy cannulation for introduction of talc.

A provisional diagnosis of talc granuloma, chemical abscess or tumour was made and exploratory thoracotomy revealed a tumour involving the chest wall, lung, and pleura which, on histological examination, showed adenocarcinoma of varying degrees of differentiation and in some parts also presenting a more squamoid appearance. Numerous doubly refractile talc particles were intimately associated with the tumour and fibrous tissue. Shortly after excision the patient developed evidence of systemic dissemination of the disease and died four months later. The possibility of this tumour being induced by the talc is discussed.

A brief review is made of the various forms of talc used in surgery over the past 40 years and attention is drawn to the significance of the proportion of asbestos mineral which is present in talc as mined in various parts of the world.
\end{abstract}

We do not consider that this is a case of mesothelioma of the pleura.

For over 30 years iodized talc pleurodesis has been a well tried and almost universally accepted method of treating recurrent spontaneous pneumothorax. Gowar (1941), in searching for a material to produce pleural symphysis, concluded that talc was superior to all the other substances he had investigated. The powder is most conveniently introduced using an insufflator and thoracoscope, a relatively minor procedure which may be carried out under local anaesthesia with a little sedation: but, as the initial reaction may be extremely painful, general anaesthesia is to be preferred.

After insertion of the thoracoscope and inspection of the lung for cysts or bullae the visceral and parietal layers of the pleura are coated with a thin layer of talc. An intercostal tube is inserted and connected to an underwater seal to which suction may be applied. The tube is removed after chest films have shown the lung to be satisfactorily expanded and bubbling has ceased for 24 hours.

The failure rate following this method has been extremely low. Two cases in a hundred required Requests for reprints: J. W. Jackson, F.R.C.S., Thoracic Surgical
Unit, Harefield Hospital, Harefield, Middx another poudrage because the lung had not become adherent. Both developed their recurrence of pneumothorax before leaving hospital. None of the other cases required further attention to the side treated. In a few patients the degree of pleural thickening was more than had been expected.

\section{CASE REPORT}

Mr. A. A. aged 37, a litho camera operator with the Stationery Office, was admitted to hospital with a right-sided spontaneous pneumothorax in Mav 1968. It resolved without treatment but recurred early in July when iodized talc pleurodesis was advised and carried out. An apical intercostal tube was inserted and $10 \mathrm{~g}$ of $1 \%$ iodized talc was insufflated through a separate cannula inserted from the right axilla. The lung expanded completely without air leak and the tube was removed after four days. The chest film was satisfactory in September. He attended in January and September 1970 because of chest pain 'localized to near the thoracoscopy incision' and was given an intercostal block with no relief. Because his pain was so persistent and getting worse in spite of treatment he was readmitted to hospital in November 1970 . He was thin, drawn looking, and obviously in pain and 


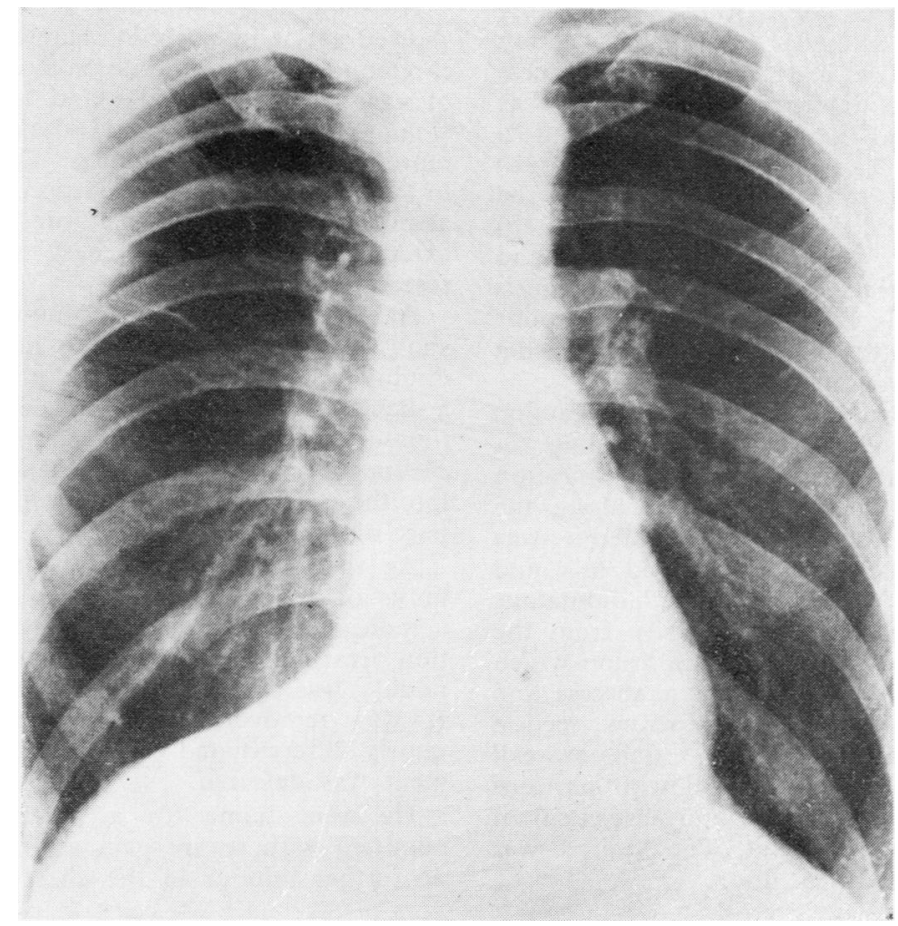

(a)

FIG. 1. (a) $P A$ chest radiograph; (b) $11 \mathrm{~cm}$ tomogram (AP projection) showing peripheral lesion in right upper zone.

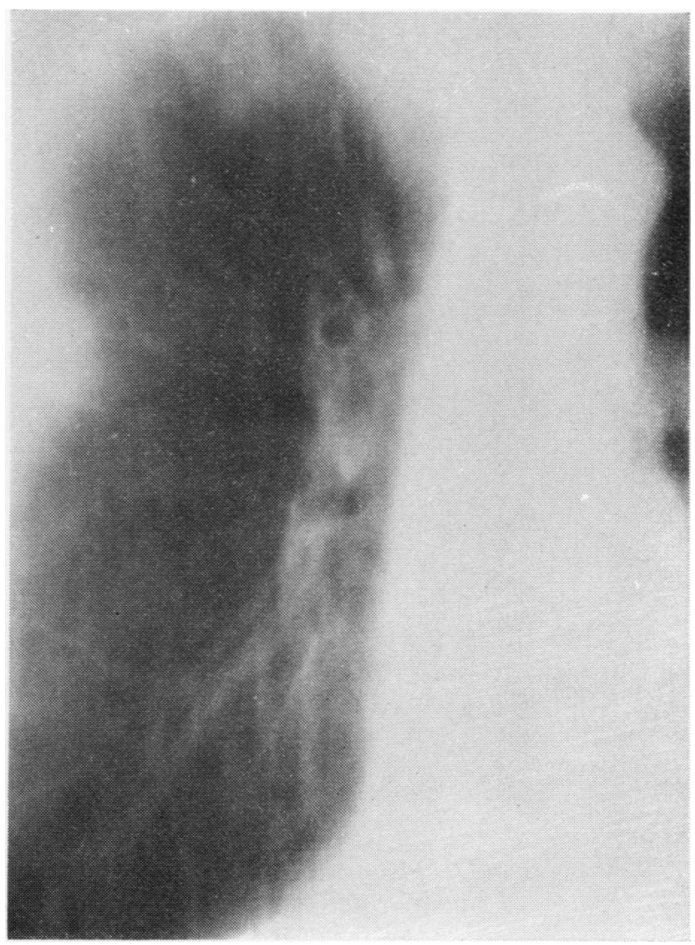


movements of the right chest were considerably restricted. There was no inflammation in relation to the previous scars. He had pain and tenderness along the right fourth intercostal space. He was afebrile with a normal white cell count and a sedimentation rate of 13. A chest film (Fig. 1a) showed an ill-defined triangular shadow at the periphery of the right mid zone. Tomograms (Fig. 1b) suggested a thickened pleura in this region and possibly some rib erosion. A provisional diagnosis of talc granuloma, sterile chemical abscess or tumour was made. In view of his persistent and increasing pain exploratory thoracotomy was advised.

At operation an apparent inflammatory reaction between the fourth and fifth ribs, suggesting an underlying tumour or abscess, was found. Aspiration revealed no pus. The chest was opened along the upper border of the sixth rib. The pleura was adherent with plaques resembling iodized talc and what was described as a mild granulomatous reaction. The lung separated fairly easily from the chest wall except in relation to the main lesion which looked and felt more like tumour than abscess and appeared to be infiltrating lung. Frozen section suggested a poorly differentiated squamous-cell carcinoma. Excision of the chest wall with portions of the fourth, fifth, and sixth ribs and a segment of underlying lung was carried out. The wound was closed with an underwater seal drain.
Histological examination of the resected specimen showed carcinoma, predominantly clear-celled adenocarcinoma, partly undifferentiated, with some areas of well-marked glandular and tubular differentiation (Fig. 2) and a few solid darkly staining foci of more squamoid appearance. The tumour appeared to have arisen in a portion of adherent lung associated with an area of old fibrous scarring and extended through the chest wall tissues to the resection limits.

At the margins of the tumour mass the pleura showed a mild granulomatous reaction and numerous doubly refractile talc particles which continued in a band of dense fibrous tissue running across the tumour corresponding to the plane of the invaded pleura. Talc particles also extended from this region into the scar tissue associated with the intrapulmonary part of the tumour (Fig. 3).

As the tumour reached to the inner and outer limits of excision it was planned to give the patient a radical course of radiotherapy to the whole operation area. Three weeks after operation a firm discrete nodule was found in the anterior abdominal wall. It was removed and on section showed similar poorly differentiated carcinoma. Further active treatment was deferred.

He went home for a short while but was readmitted with severe pain and radiological evidence of further tumour in the chest wall. This increased

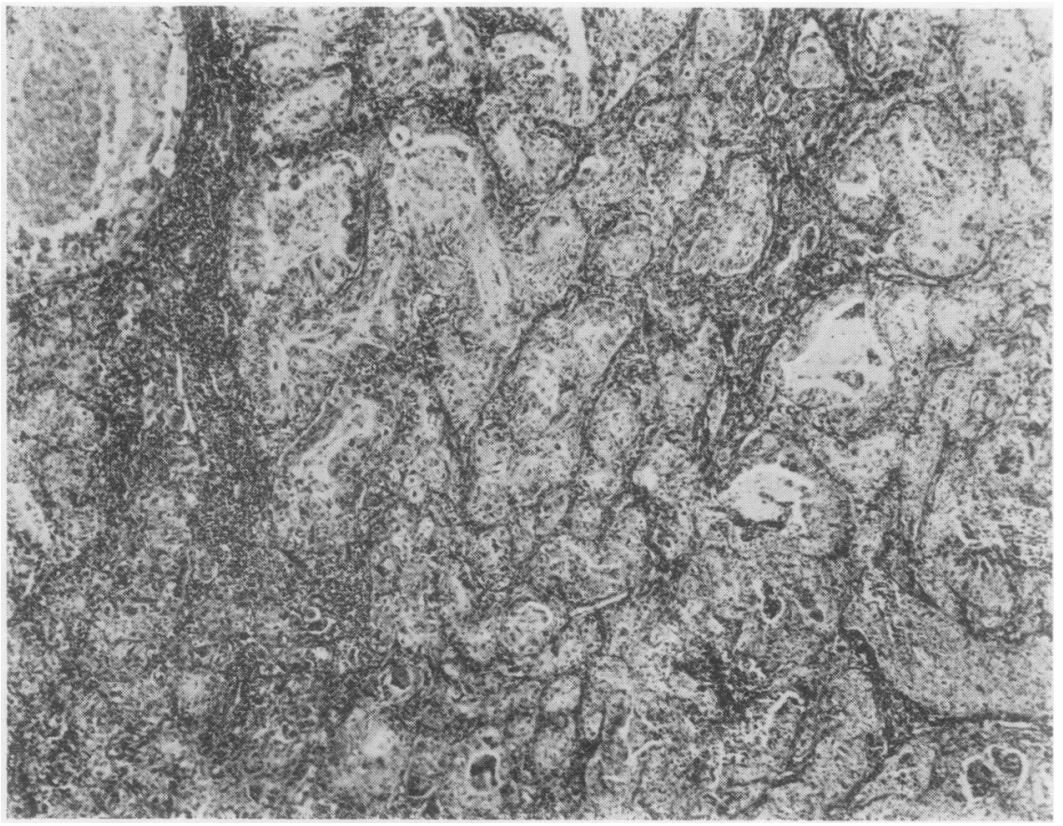

FIG. 2. Photomicrograph of tumour showing a clear-celled adenocarcinoma with areas of glandular differentiation. $H$ and $E \times 25$. 


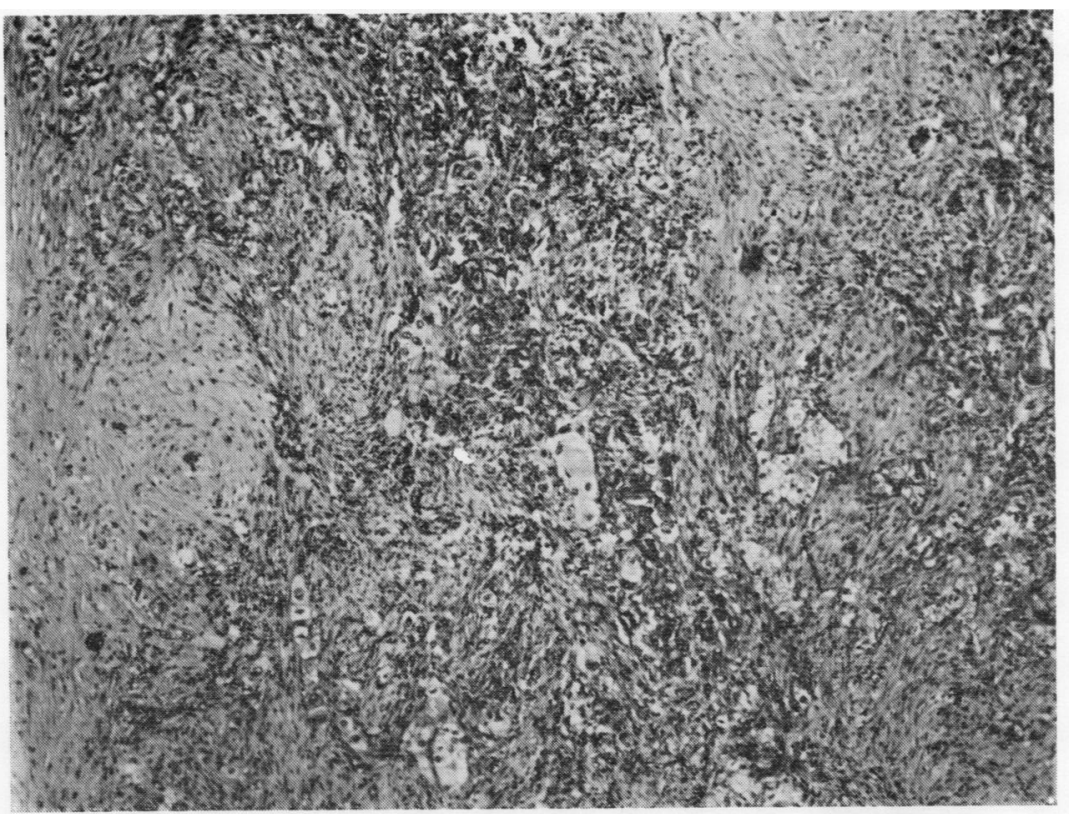

(a)

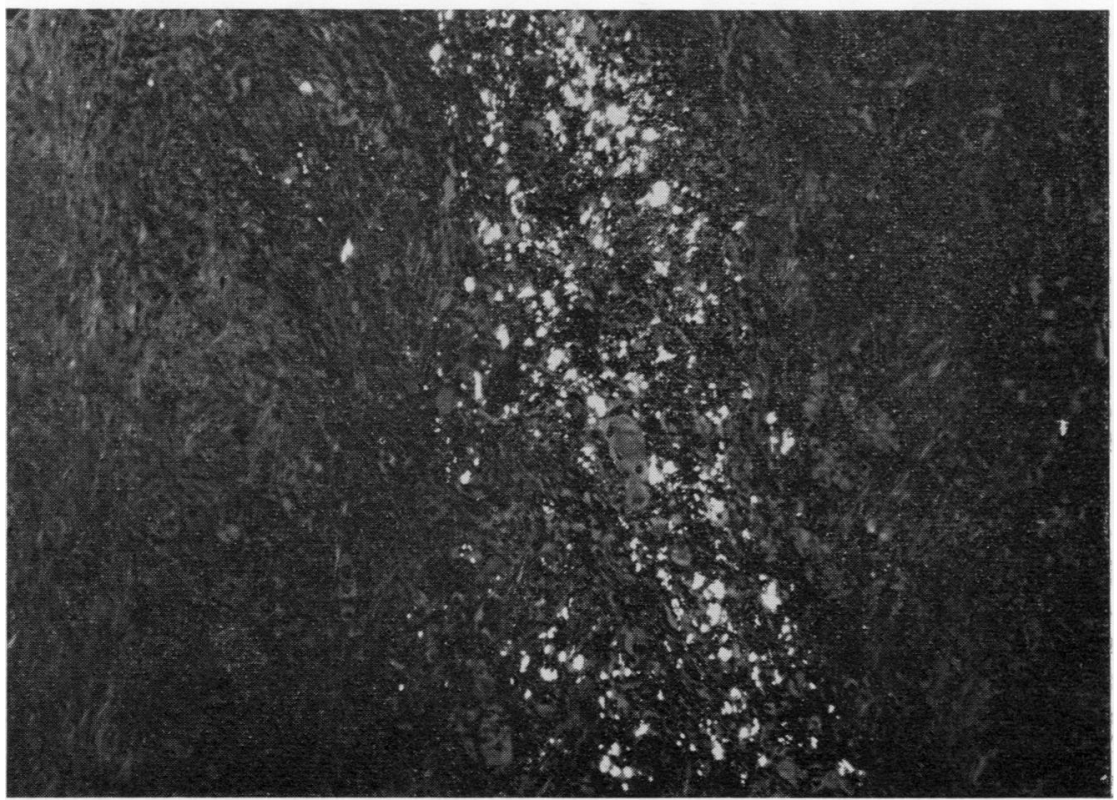

(b)

FIG. 3 (a). Photomicrograph of undifferentiated carcinoma in scar tissue in lung. $H$ and $E \times 50$.

(b) The same field as in (a) photographed through polarizing filters to show incorporated doubly refractile talc particles. 


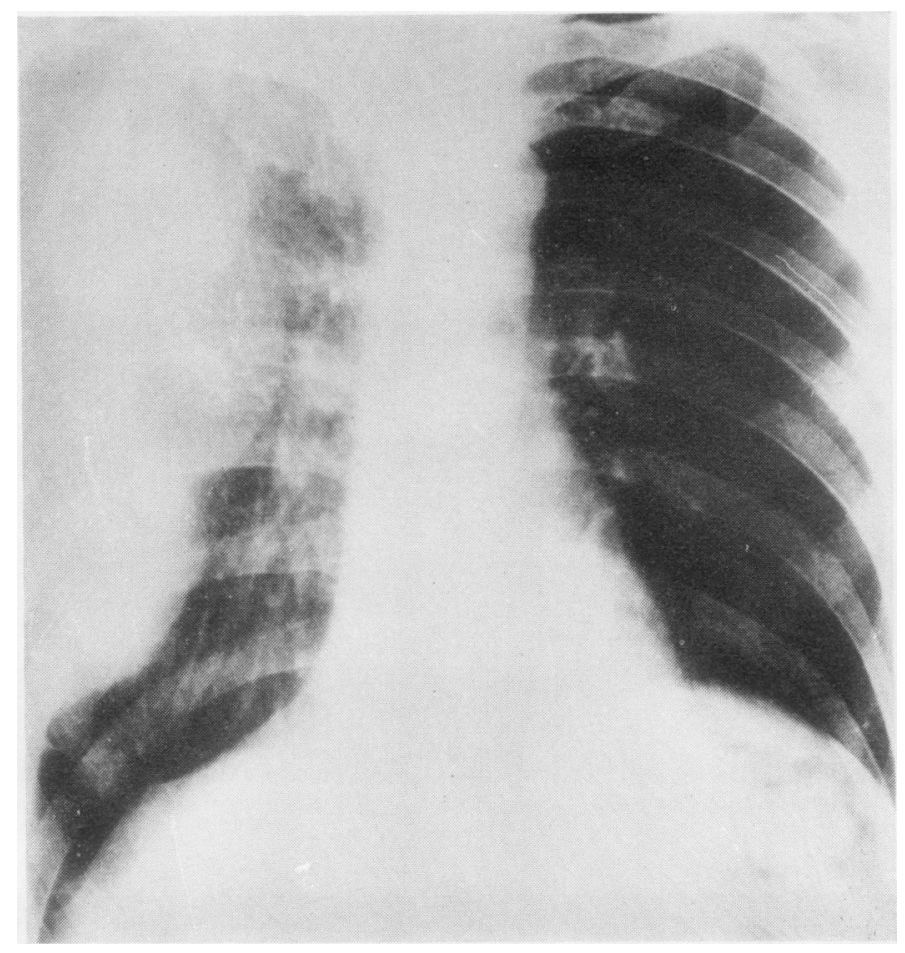

FIG. 4. Chest radiograph taken shortly before death showing the extent of recurrence of tumour.

in size rapidly (Fig. 4) until he died four months after operation. No other clinical metastases developed.

Necropsy showed a lobulated necrotic tumour. involving the anterolateral chest wall and the underlying lung with secondary deposits in the suprarenal glands.

\section{DISCUSSION}

To many surgeons 'talc' and 'glove powder' are synonymous. Various substances have been used and none has been entirely free from trouble. Antopol (1933) described peritoneal reaction to the preparation that was being used as glove powder up to that time. Lycopodium, a yellow tasteless and odourless dusting powder, had been used for years in the pharmacy to prevent the agglutination of pills in a box. It is a vegetable sulphur derived from the spores of the club moss Lycopodium clavatum (wolf's foot). Its use as a glove powder was abandoned in favour of mineral talc which consists of :

$$
\begin{array}{lr}
\text { Magnesium silicate } & 82.7 \% \\
\text { Calcium carbonate } & 8.7 \% \\
\text { Magnesium carbonate } & 7.6 \%
\end{array}
$$

It is this preparation, to which iodine $\left(\frac{1}{2}-1 \%\right)$ is added, that has been used for pleurodesis.

German (1943) described granuloma formation from this form of talc and emphasized its dangers. There were a number of similar articles published at that time.

The modern Bisorb powder, introduced in 1947 , is a mixture of amylose and amylopectins, derived from corn-starch and magnesium oxide. It was said to produce little foreign body reaction because, as its name indicates, the starch derivatives are in such a form that they are readily absorbed. Neeley and Davies (1971) have shown that it is not as harmless as expected and they describe a granulomatous peritoneal reaction which develops within a few weeks of surgery. 
It appears that this product does not have the long-term problems of the earlier preparations.

An increasing awareness of the problems of asbestosis and its association with pleural mesothelioma made us wonder if the chemical irritation caused by the talc and iodine might induce a pleural tumour. Such a probability was postulated by Hinson at a meeting in 1966 and in the discussion that followed Dr. P. J. Lawther reported that in the United States many toilet preparations of talc contained chrysotile which had not been deliberately added but occurred naturally in the mineral deposit. Merliss (1971) likewise reports that very few mineral talcs are free of asbestos fibres. Talcs from Vermont mines are relatively pure but those from New York and California are heavily contaminated.

Miller et al. (1971) drew attention to the significance of sublight microscopic mineral particles in talc and described varying amounts of asbestos

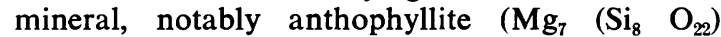
$\left.(\mathrm{OH})_{2}\right)$ and tremolite $\left(\mathrm{Ca}_{2}, \mathrm{Mg}_{5}\left(\mathrm{Si}_{8} \mathrm{O}_{22}\right)(\mathrm{OH})_{2}\right)$, that may be associated with the natural product. They describe talc pneumoconiosis in a man of 70 who spent nine years cleaning ventilators in a factory using talc. The lungs showed fibrosis and granulomata with lymphocytes and epithelioid and giant cells.

Hopkins and Taylor (1970) described two cases of pulmonary talc granulomatosis associated with the illicit use of methylphenidate hydrochloride (Ritalin). This drug is a mild stimulant and antidepressant similar to the amphetamines, normally taken by mouth but administered intravenously by addicts. Talc is used as a filler in the tablet form of the drug, and when introduced into the circulation causes a granulomatous reaction in the pulmonary vessels leading to intravascular thrombosis and pulmonary hypertension. One of the cases they describe also had a 'coin' lesion in the left upper lobe which turned out to be an undifferentiated malignant neoplasm with a large area of central necrosis. The remainder of the lung showed a granulomatous reaction and birefringent crystalline material with the typical appearances of talc.

We feel that our case was a 'scar carcinoma' which became manifest after iodized talc pleurodesis. The tumour had apparently developed in close relation to the site of axillary cannulation.

Talc particles had become incorporated not only in the invaded scarred pleura but also in the scar tissue in the intrapulmonary part of the tumour. It seems unlikely that the talc played a causative role in the formation of the tumour but there can be little doubt that the pleurodesis facilitated the early spread of tumour to the chest wall along the cannula track.

It is possible that the tumour in Hopkins and Taylor's (1970) patient was provoked by a similar mechanism.

\section{REFERENCES}

Antopol, W. (1933). Lycopodium granuloma. Archives of Pathology, 16, 326.

German, W. M. (1943). Dusting powder granulomas following surgery. Surgery Gynecology and Obstetrics, 76, 501.

Gowar, F. J. S. (1941). The post-operative complications of pulmonary lobectomy. British Journal of Surgery, 29, 3.

Hinson, K. F. W. (1966). Asbestosis and neoplasia. In Some Aspects of Carcinoma of the Bronchus and Other Malignant Diseases of the Lung: A Symposium held at King Edward VII Hospital, Midhurst, 4-5 July 1966, p. 19, edited by D. Teare and J. Fenning.

Hopkins, G. B. and Taylor, G. D. (1970). Pulmonary talc granulomatosis. A complication of drug abuse. American Review of Respiratory Diseases, 101, 101.

Merliss, R. R. (1971). Talc treated rice and Japanese stomach cancer. Science, 173, 1141.

Miller, A., Teirstein, A. S., Bader, M. E., Bader, R. A., and Selikoff, I. J. (1971). Talc pneumoconiosis: Significance of sublight microscopic mineral particles. American Journal of Medicine, 50, 395.

Neeley, J., and Davies, J. D. (1971). Starch granulomatosis of the peritoneum. British Medical Journal, 3, 625. 